\title{
Strength Characteristics of Concrete with Brine and Olive Oil Mill Wastewaters
}

\author{
Husein A. Alzgool \\ Department of Civil Engineering, Faculty of Engineering, Ajloun National University, P.O. Box 43, Ajloun 26810, Jordan.
}

\begin{abstract}
Concrete industry consumes large amount of water during mixing, curing and washing that in role increase the demand pressure on water resources especially in countries that meet water scarcity. On the other hand, large amount of wastewaters are discharged to surrounding streams from desalination plants and olive oil mills that in role impacted the surrounding environment and deteriorate water quality. We have tested the compressive strength of concrete mixtures mixed with brine water and olive oil mill wastewater added at different percentages as a part of sustainably development and water reuse management. The percentages of added brine water and olive oil wastewater to freshwater adjusted to $5 \%, 7.5 \%, 10 \%$, $15 \%, 20 \%, 30 \%$ and $40 \%$, and the compressive strengths were tested for curing days of 7, 14, 21, and 28 days. Triplicate samples are prepared for each percentage and curing day and mean values were calculated and compared with reference concrete sample prepared with freshwater. The compressive strength have been noticed to decrease with the increase in the percentage of added olive oil mill wastewater with clear change in the surface color and workability. Furthermore, the strength rate of concrete samples has increased in a linear manner with increasing the percentage of brine water to freshwater.
\end{abstract}

Keywords: Compressive Strength, Olive Oil Mill, Brine Water, Concrete Mixes.

\section{INTRODUCTION}

Concrete has reported to be the most material used worldwide due to its compressive strength and durability [1]. Twelve billion tons of concrete has been estimated to be consumed in the world making concrete a significant contributor to air pollution and a major consumer of substantial quantities of freshwater [2,3]. Tons of green-house gases are released into the atmosphere during concrete production processes that in role impacted the environment. It has estimated that about 1.4 billion tons of $\mathrm{CO}_{2}$ are produces in 1995 forming $7 \%$ of the total produced $\mathrm{CO}_{2}$ worldwide [3]. Many studies have shown that concrete industry consumes high volume of preliminary materials, releases high amount of green-house gases during cement production, required high energy, produces tons of solid wastes and consume large amount of freshwater [4]. In semi-arid regions, where Jordan is located, freshwater resources are rarely available. This in role making water reuse options an essential component of water resources management and sustainable development. While concrete industry consuming one trillion gallons of water each year worldwide excluding waters used for washing and curing, this amount of water boost the stress on the available water resources in semiarid regions [5]. In the other hand, wastewater discharged from wastewater treatment plants, desalination plants and olive oil mills affects surrounding streams and deteriorates surface and ground water quality [6]. These wastewater sources can be reused in many local practices in order to minimize its impact on the environment.

Many studies have tested the use of salt water in concrete mixture, e.g. see water, and obtained compressive strength of concrete cubes at different curing days $[2,7,8.9]$. Further tests have been performed for curing concrete cubes in salt water. The results of these studies have shown that concrete made with salts water have higher early strength in compare with normal concrete but gradually decrease in strength have been notices with age [2]. Further investigations have performed for curing concrete in solution with sodium sulfate and concrete have shown to loss mass due to the lime filler content $[10,11]$.

In this study we have investigated the current state of knowledge of the use of Brine water and olive oil mill wastewater in the concrete industry and directing future researched to investigate the relative environmental impact and sustainability of use these waters in concrete production.

\section{MATERIALS AND METHODS}

\section{i. $\quad$ Cement}

Physical and chemical properties of ordinary Portland cement are given in American Standard Testing Materials (ASTM C150). Aggregate used in preparing mixes meet the specifications of national standards where the percentages of course aggregate, fine aggregate and sand were $40 \%, 30 \%$, and $30 \%$, respectively (Table 1 ). The maximum nominal size of the course aggregate was $22 \mathrm{~mm}$ and passing $19.5 \mathrm{~mm}$. The fine aggregate passed $4.7 \mathrm{~mm}$ during sieve analysis and sand has selected in N30-N200. The water-cement ratio has been fixed to 0.45 and the mix ratios were 1:2:4 for all samples. 
International Journal of Engineering Research and Technology. ISSN 0974-3154, Volume 13, Number 10 (2020), pp. 2831-2838

(C) International Research Publication House. https://dx.doi.org/10.37624/IJERT/13.10.2020.2831-2838

Table 1. Size and quantities of aggregates used in mixes.

\begin{tabular}{|c|c|c|}
\hline Aggregate Type & Percentage \% & Passing number \\
\hline Course aggregate C.A & 40 & $\frac{3}{}^{\prime \prime}(19 \mathrm{~mm})-\frac{1^{\prime \prime}}{2}(9.5 \mathrm{~mm})$ \\
\hline Fine Aggregate F.A & 30 & No. $4(4.75 \mathrm{~mm})-30 \mathrm{~mm}$ \\
\hline Sand & 30 & $2 \mathrm{~mm}-0.075 \mathrm{~mm}$ \\
\hline
\end{tabular}

Portable water has been used for preparing reference samples. The water is free from any impurities and $\mathrm{pH}$ value below 8 . Brine water has collected from nearby inland desalination plant directly from discharge outlet. The Brine water is filled in sealed PVS containers and transported to the laboratory. Physico-chemical properties of brine water has measured insitu and the brine water is used within three days from sampling to ensure not much properties are changed. Olive oil mill wastewater is collected from olive oil mill $5 \mathrm{~km}$ far from university campus. The samples has collected directly from discharge outlet and transported in sealed-nonreactive containers. The olive oil mill wastewater has used within three days after collection to ensure not much properties are changed and physio-chemical properties of samples are collected from the plant's laboratory.

\section{ii. $\quad$ Mix DESIGN}

All concrete mixes were prepared in this study were cured in freshwater (204 samples). The mixes were tested at ages 7, 14, 21 and 28 days for compression tests. See Table 2. All specimens are gathered and cured in freshwater after 24 hours of casting up to the testing date 7, 14, 21, and 28 days. 12 mixes were mixed with fresh water, 96 mixes were mixed with olive oil mill wastewater at different percentage $(2.5 \%, 5 \%, 7.5 \%$, $10 \%, 15 \%, 20 \%, 30 \%$ and $40 \%$ ), and 96 mixes were prepared using Brine water replacement at different percentages $(2.5 \%$, $5 \%, 7.5 \%, 10 \%, 15 \%, 20 \%, 30 \%$ and $40 \%$ ). The targeted slump for all mixes ranged between 50 and $70 \mathrm{~mm}$ and all materials used in preparing mixes were weighed as per the required proportions.

Table 2. Concrete mix count and description of curing conditions for samples prepared with freshwater (FW), and different percentages of added olive oil mill wastewater $(\mathrm{O})$ and brine water $(\mathrm{B})$.

\begin{tabular}{|c|c|c|c|c|c|c|c|}
\hline $\begin{array}{l}\text { Mixing } \\
\text { Water }\end{array}$ & $\begin{array}{l}\text { Replacement } \\
\text { Ratio }\end{array}$ & $\begin{array}{l}\text { Number } \\
\text { of } \\
\text { samples }\end{array}$ & 7 Days & $\begin{array}{l}14 \\
\text { Days }\end{array}$ & $\begin{array}{l}21 \\
\text { Days }\end{array}$ & $\begin{array}{l}28 \\
\text { Days }\end{array}$ & $\begin{array}{l}\text { Curing } \\
\text { Water }\end{array}$ \\
\hline FW & & 12 & 3 & 3 & 3 & 3 & $\begin{array}{l}\text { FW at } \\
20{ }^{\circ} \mathrm{C}\end{array}$ \\
\hline O/FW & $\begin{array}{l}2.5 \% \\
5 \% \\
7.5 \% \\
10 \% \\
15 \% \\
20 \% \\
30 \% \\
40 \%\end{array}$ & 96 & $\begin{array}{l}3 \\
3 \\
3 \\
3 \\
3 \\
3 \\
3 \\
3\end{array}$ & $\begin{array}{l}3 \\
3 \\
3 \\
3 \\
3 \\
3 \\
3 \\
3\end{array}$ & $\begin{array}{l}3 \\
3 \\
3 \\
3 \\
3 \\
3 \\
3 \\
3\end{array}$ & $\begin{array}{l}3 \\
3 \\
3 \\
3 \\
3 \\
3 \\
3 \\
3\end{array}$ & $\begin{array}{l}\mathrm{FW} \text { at } \\
20{ }^{\circ} \mathrm{C}\end{array}$ \\
\hline B/FW & $\begin{array}{l}2.5 \% \\
5 \% \\
7.5 \% \\
10 \% \\
15 \% \\
20 \% \\
30 \% \\
40 \%\end{array}$ & 96 & $\begin{array}{l}3 \\
3 \\
3 \\
3 \\
3 \\
3 \\
3 \\
3\end{array}$ & $\begin{array}{l} \\
3 \\
3 \\
3 \\
3 \\
3 \\
3 \\
3\end{array}$ & $\begin{array}{l} \\
3 \\
3 \\
3 \\
3 \\
3 \\
3 \\
3\end{array}$ & $\begin{array}{l} \\
3 \\
3 \\
3 \\
3 \\
3 \\
3 \\
3\end{array}$ & $\begin{array}{l}\mathrm{FW} \text { at } \\
20{ }^{\circ} \mathrm{C}\end{array}$ \\
\hline
\end{tabular}




\section{iii. $\quad$ Compression test}

Triplicate cube samples of $15 \mathrm{~mm} \times 15 \mathrm{~mm} \times 15 \mathrm{~mm}$ have prepared for each W/C of different water source and for specimen age using compression testing machine. Average strength value is calculated for the three samples per each patch and compared with corresponding reference samples of same $\mathrm{W} / \mathrm{C}$ ratio.

\section{RESULTS AND DISSCUSSION}

i. Strength rate at different water content

A. Olive oil mill wastewater impact

All concrete specimens that contains olive oil mill wastewater in their mixture had harder surfaces than the other specimens mixed with freshwater and brine water. We have noticed that specimens mixed with olive oil mill wastewater had also better workability than the other mixes. However, surface color have also noticed to change for specimens that mixed and cured in seawater to be darker that the specimens mixed and cured in freshwater (Fig.1 and 2). This has also observed for samples of which mixed with brine water indicating the effect of dissolved salts on the specimen's surface color.

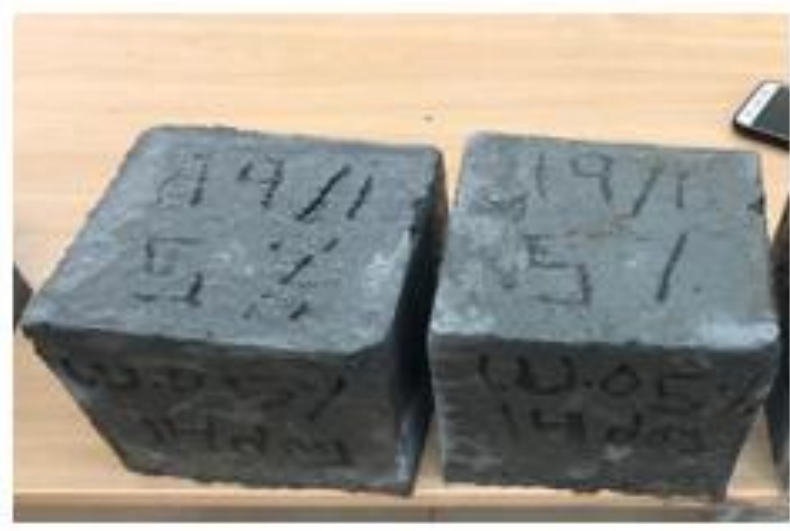

a. $\mathrm{O}-\mathrm{W} \mathbf{5 \%}$

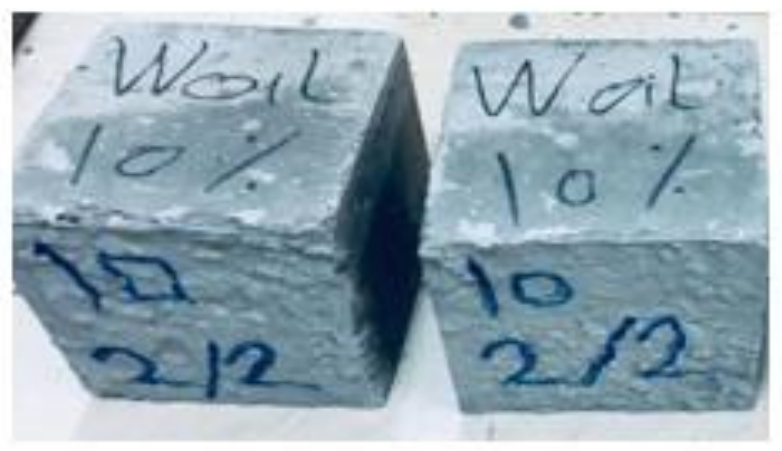

c. $\mathrm{O}-\mathrm{W} 10 \%$
A substantial decrease in compressive strengths has been observed with the increase in olive oil mill wastewater added to samples. The rate of strength in all samples have increased with time and reached its maximum at 28 day curing (Fig. 3). However, the rates of increase in all samples was still increasing after 28 days in a negligible rate especially for samples of a percentage higher than 7.5. The average percentage increase in compressive strength have been observed after 14 days of about $30 \%$ for all samples mixed with olive oil mill wastewater and the maximum average have registered for high percentage of added wastewater. This refers to the low rate of gained strength few days after curing for samples mixed with olive oil mill wastewater indicated that at high percentage of wastewater the chemical reaction has inhabited. However, slight increase in strength percentage has registered after 21 days curing reaching its maximum of $22 \%$ for samples of higher than $15 \%$ of its water content is olive oil wastewater with average increase 12\% (Fig.3). We don't see any decrease in compressive strength with curing time for all samples mixed with added olive oil wastewater indicating that maximum strength has not reached. With the low percentage increase in strength rate, we don't see that the strength value will meet the national standards for concrete strength value.

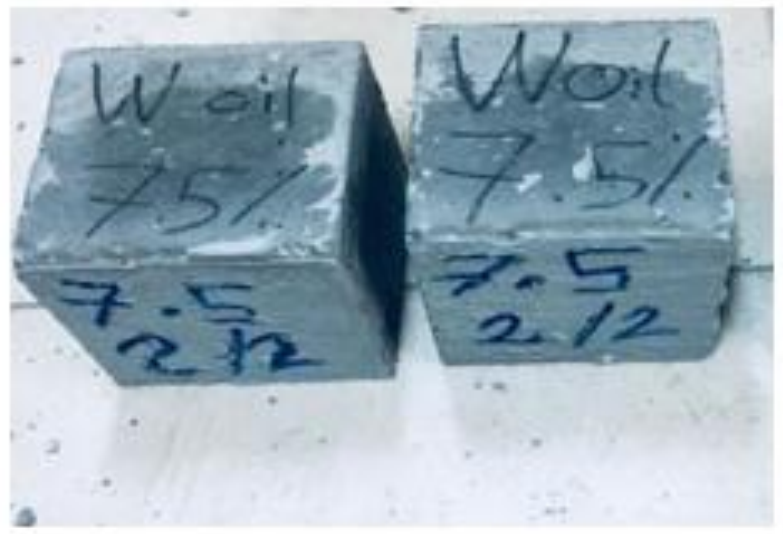

b. $\mathrm{O}-\mathrm{W} 7.5 \%$

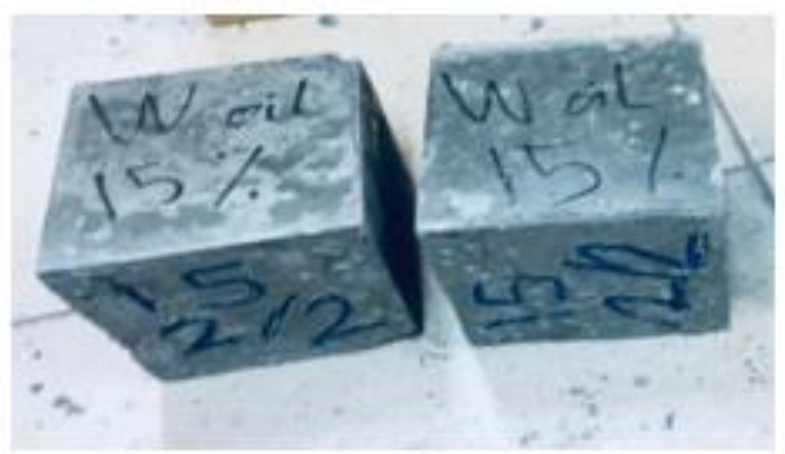

d. O-W $15 \%$

Figure 1: Variation in the surface color for mixes of different olive oil mill wastewater percentage (O-W). Dark-green surface color for specimens of high olive oil mill wastewater percentages. 


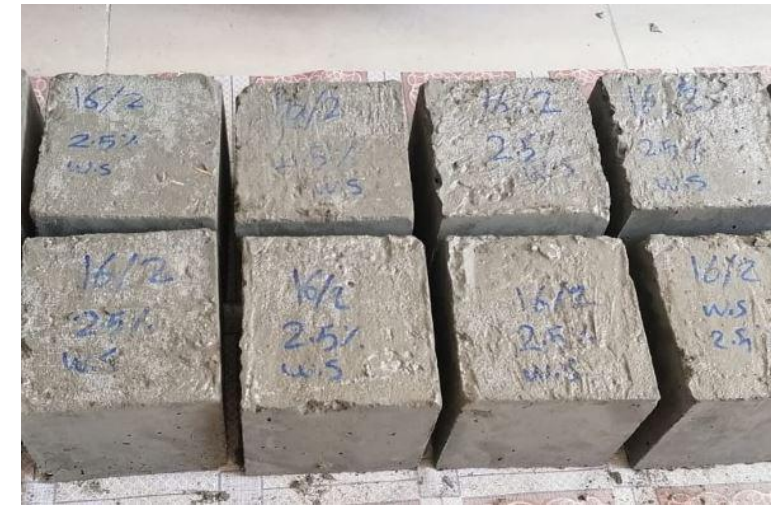

a) S-W $2.5 \%$

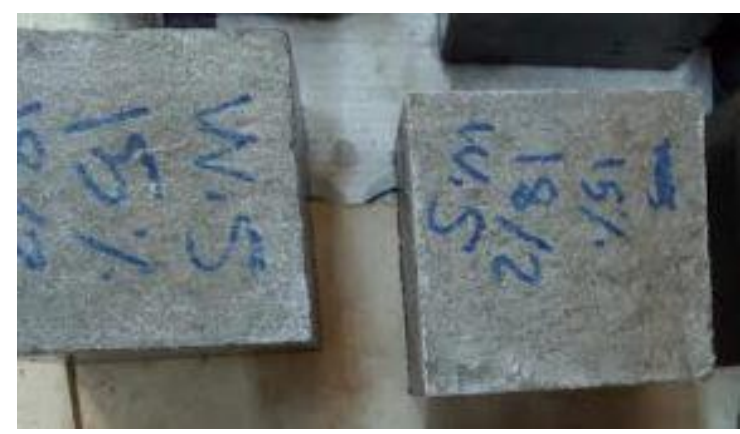

c. S-W $15 \%$

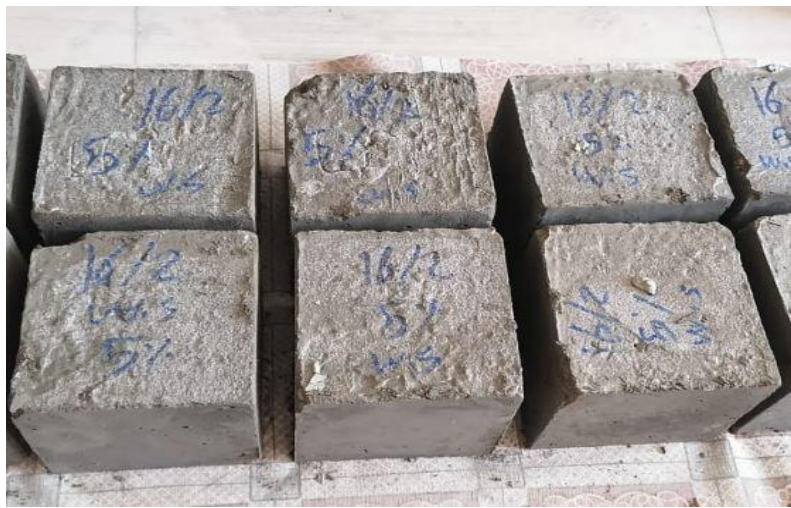

b. S-W $5 \%$

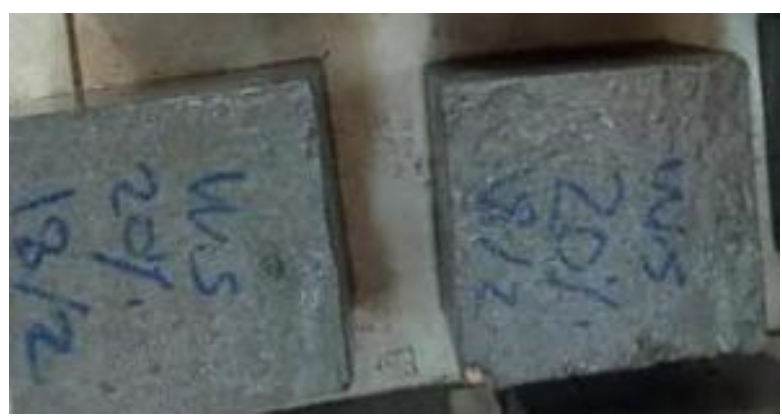

d. S-W $20 \%$

Figure 2: No change in the surface color for mixes of different brine water content (S-W).

A substantial decrease in compressive strengths has been observed with the increase in olive oil mill wastewater added to samples. The rate of strength in all samples have increased with time and reached its maximum at 28 day curing (Fig. 3). However, the rates of increase in all samples was still increasing after 28 days in a negligible rate especially for samples of a percentage higher than 7.5. The average percentage increase in compressive strength have been observed after 14 days of about $30 \%$ for all samples mixed with olive oil mill wastewater and the maximum average have registered for high percentage of added wastewater. This refers to the low rate of gained strength few days after curing for samples mixed with olive oil mill wastewater indicated that at high percentage of wastewater the chemical reaction has inhabited. However, slight increase in strength percentage has registered after 21 days curing reaching its maximum of $22 \%$ for samples of higher than $15 \%$ of its water content is olive oil wastewater with average increase $12 \%$ (Fig.3). We don't see any decrease in compressive strength with curing time for all samples mixed with added olive oil wastewater indicating that maximum strength has not reached. With the low percentage increase in strength rate, we don't see that the strength value will meet the national standards for concrete strength value.

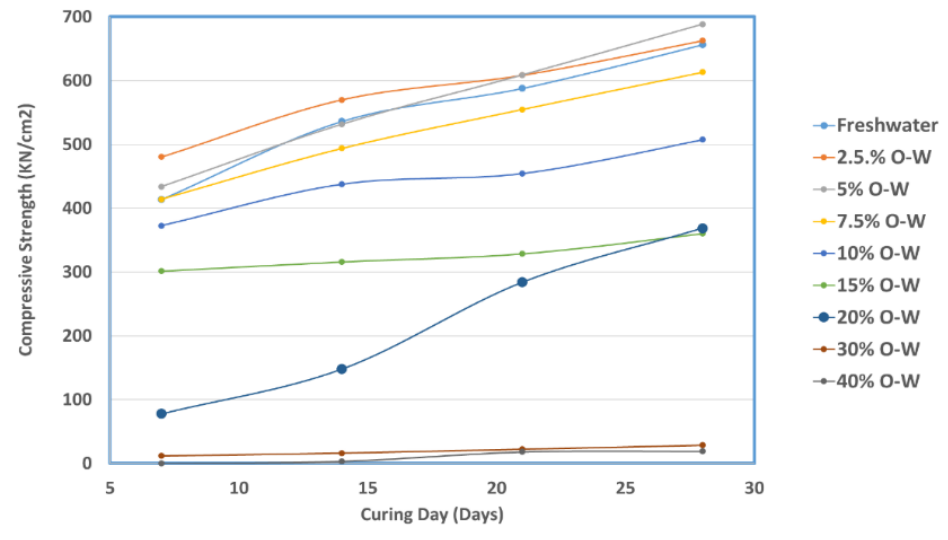

Figure 3: Compressive strength $\left(\mathrm{KN} / \mathrm{cm}^{2}\right)$ of concrete mixes of different olive oil mill wastewater-water ratio $(\mathrm{O}-\mathrm{W})$ for $7,14,21$ and 28 curing days. 
International Journal of Engineering Research and Technology. ISSN 0974-3154, Volume 13, Number 10 (2020), pp. 2831-2838

(C) International Research Publication House. https://dx.doi.org/10.37624/IJERT/13.10.2020.2831-2838

\section{B. Brine water impact}

We have noticed that all specimens mixed with brine water gaining compressive strength with curing time excepted samples at Brine/freshwater ratios of $20 \%$ and $30 \%$ where the strength is temporary decrease after 7 and 14 days, respectively (Fig. 4). In all samples mixed with brine water the compressive strength have higher value than samples mixed with freshwater. Increasing in compressive strength due to salt water addition have also noticed in many studies after 28 days curing. Slight decrease after 90 days curing have also shown in the range $3.8 \%$ to $14.5 \%$ that may refer to crystallization process. We have noticed that the workability of the samples that are mixed with brine water does not changed but specimens have hard surface few hours after curing indication that dry time is faster compared with specimens mixed with freshwater. However, cement content of $350 \mathrm{~kg} / \mathrm{m}^{3}, 400 \mathrm{~kg} / \mathrm{m}^{3}$ and $450 \mathrm{~kg} / \mathrm{m}^{3}$ may vary the compressive strength of samples mixed with salt water and negative effect after 28 days curing is expected.

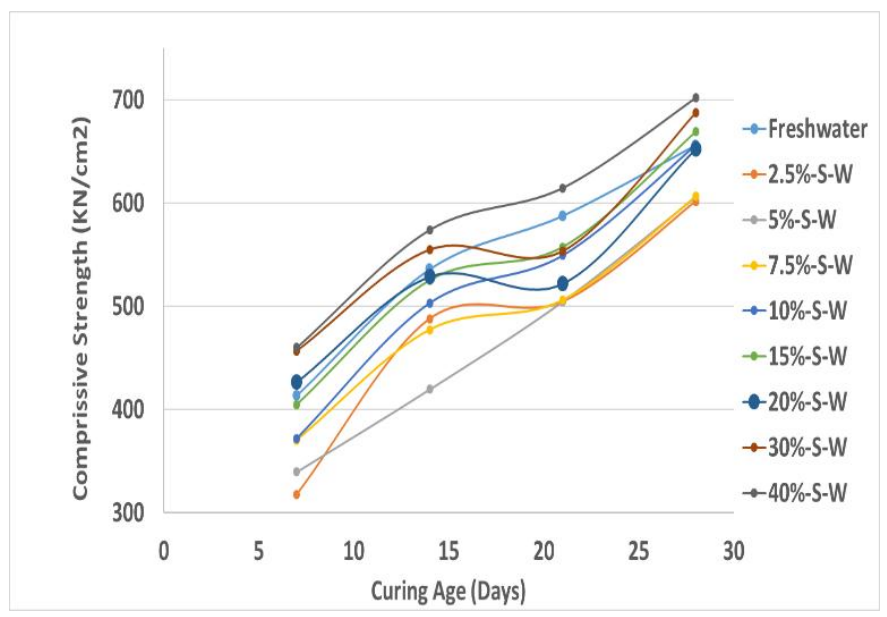

Figure 4: Compressive strength $\left(\mathrm{KN} / \mathrm{cm}^{2}\right)$ of concrete mixes if different brine water-water ration $(\mathrm{S}-\mathrm{W})$ for $7,14,21$ and 28 curing days.

Linear increase in compressive have been shown with increasing percentage of brine water added to mixers at all curing days (Fig. 5). Substantial decrease in in compressive strength have been shown after 14 days curing for all samples of different percentage of brine water added to mixes by about $20 \%$. Same result have been indicated for samples mixed with seawater indicating that salt water addition lower compressive strength after 14 days curing. More studies are needed for investigating the effect of water on chemical reaction. The effect of added brine water on compressive strength will decrease after the percentage of $40 \%$ after 28 days curing and further researches are requested to investigate the effect of using high brine water percentage for longer curing time. In all specimens, maximum strength have been gained after 28 days curing for samples that brine water enters their mixture.

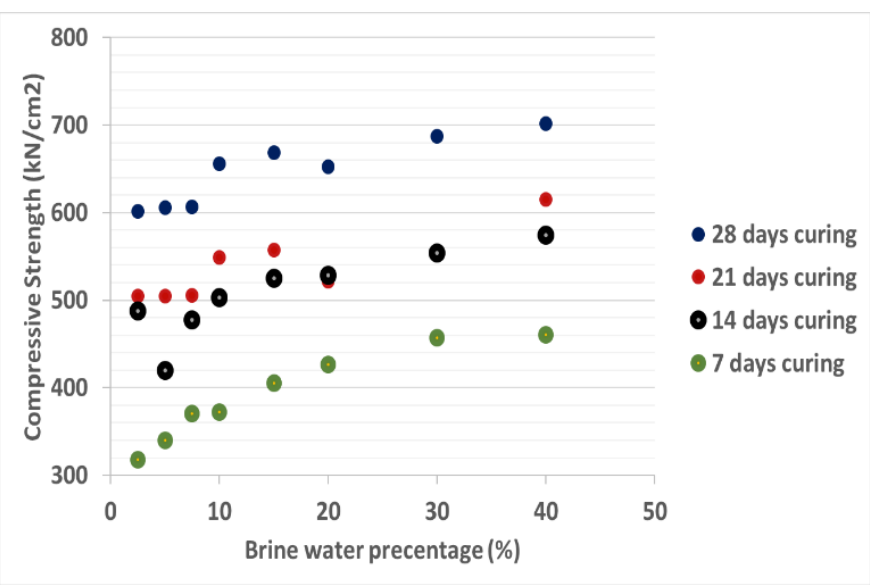

Figure 5: Linear increase in compressive strength $\left(\mathrm{KN} / \mathrm{cm}^{2}\right)$ for samples of different brine water percentage at all curing days.

C. Relative intensity of different water content and curing age

We have calculated the ratio of strength at each curing day (fn) with the intensity of 28 days in order to gain the relative compressive strength and to reflect the law of age-compressive strength for our samples. We have noticed that in most mixes of different Brine water percentage are dispersed around the logarithm line and same results have been shown for sea water where concrete made with sea water showed bigger dispersion than that of the concrete made with freshwater (Fig. 6 and Fig. 7). Linear correlation have been shown between curing age and relative intensity for samples mixed with different olive oil mill wastewater percentages.

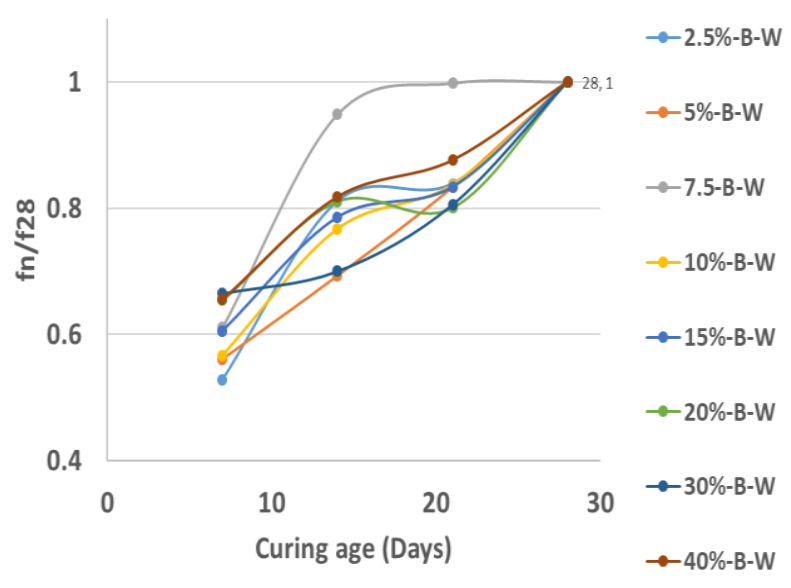

Figure 6: Relative intensity for mixes group of different percentage of Brine water to freshwater (B-W) at different curing days. 


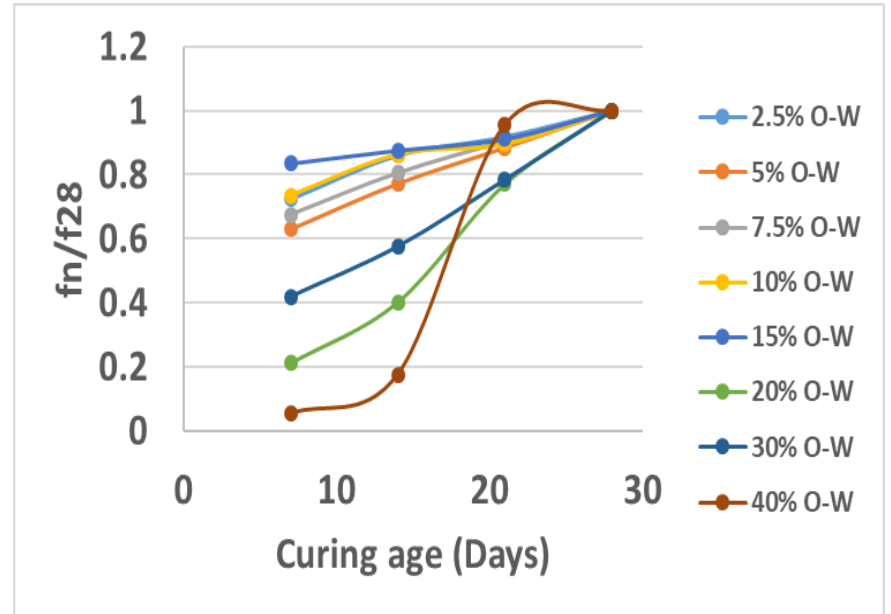

Figure 7: Relative intensity for mixes group of different percentage of olive oil mill wastewater to freshwater $(\mathrm{O}-\mathrm{W})$ at different curing days.

ii. Applicable practices
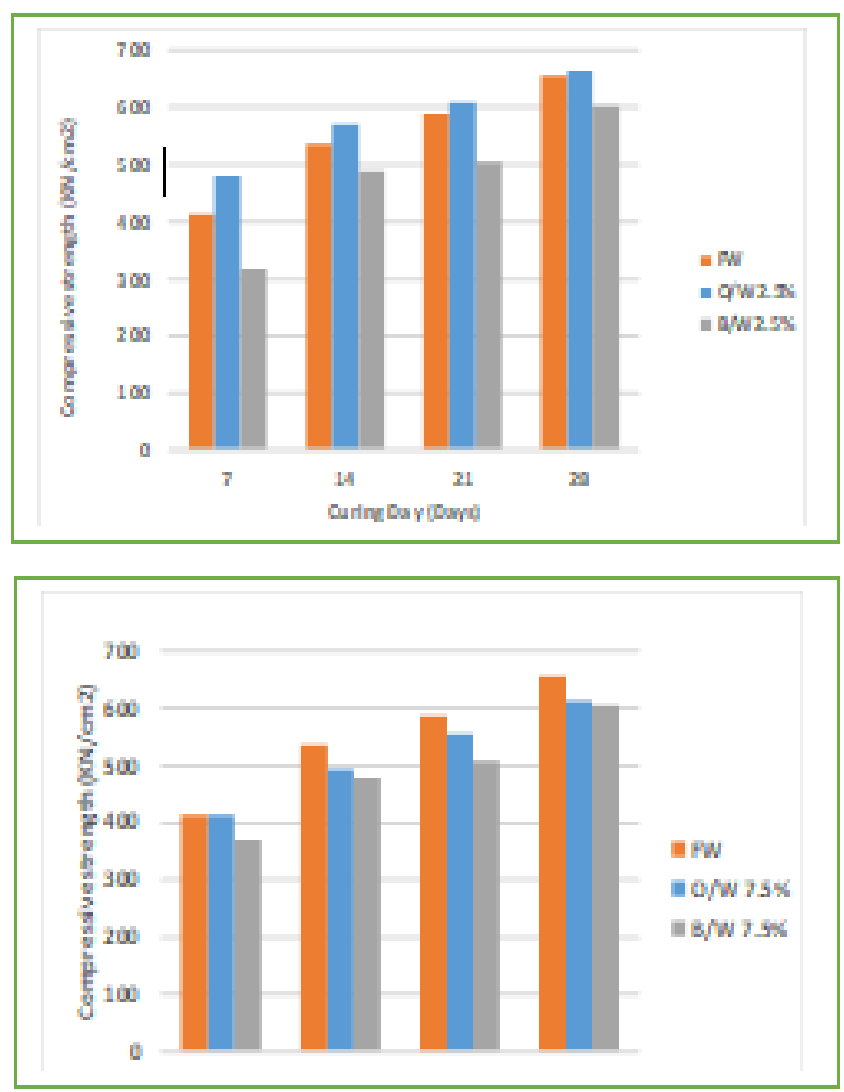

As shown in figure 8, the addition of olive oil mill wastewater to mixes at low percentage (below 10\%) will not significantly affect the compressive strength as compared with reference samples prepared with freshwater. In contrast, we have noticed a significant decrease in compressive strength at high percentage of added olive oil mill wastewater in all samples (Fig.9). At the percentage of added olive oil wastewater of $40 \%$ the compressive strength reaches zero regardless the curing day. However, olive oil mill wastewater can be used in concrete industry at low percentage and low temperature conditions. Further studies are needed to investigate the long-term impact of the use olive oil mill waster in reinforced concrete industry.

While adding high percentage of brine water to concrete mixes has shown to increase the compressive strength to the most of samples, the use of brine water in concrete industry will be suitable in paving application. Many application may require the specifications of concrete mixed with brine water like the cases where the concrete of temporary applications or for soft uses.
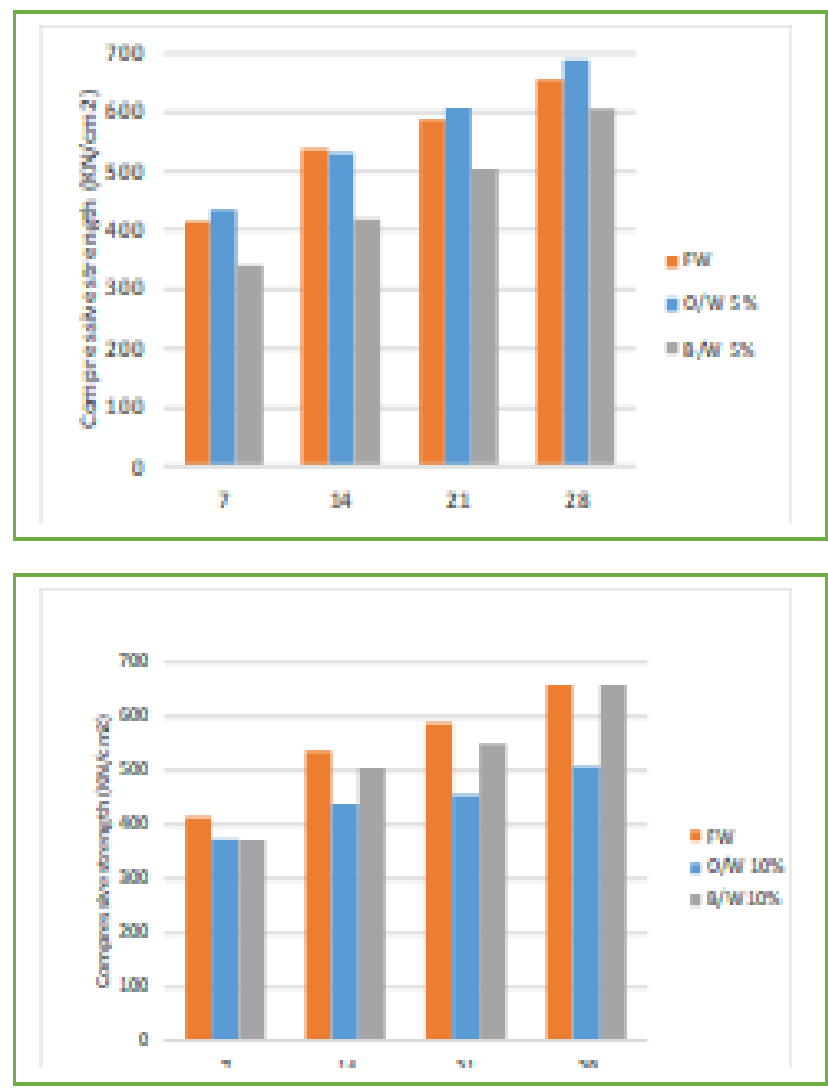

Figure 8: Compressive strength $\left(\mathrm{KN} / \mathrm{cm}^{2}\right)$ of mixes of different percentages (from 2.5 to 10 ) of olive oil mill wastewater to freshwater $\mathrm{O} / \mathrm{W}$ (blue bars) and brine water to freshwater B/W (grey bars). 

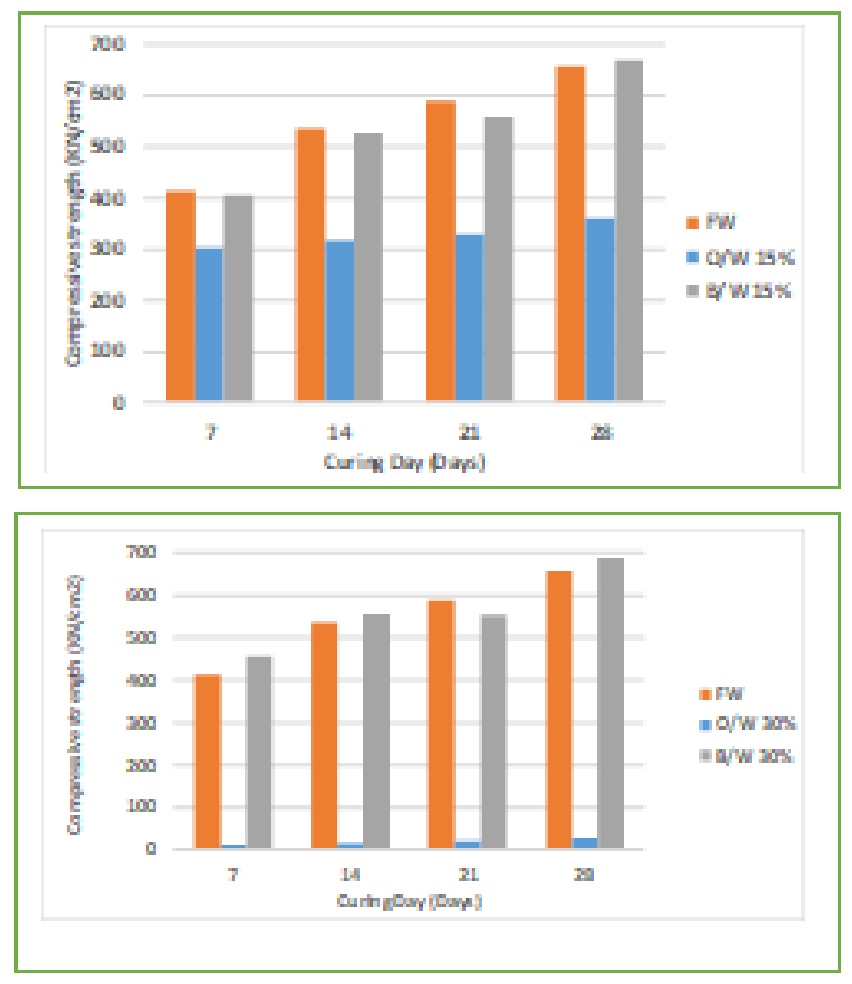
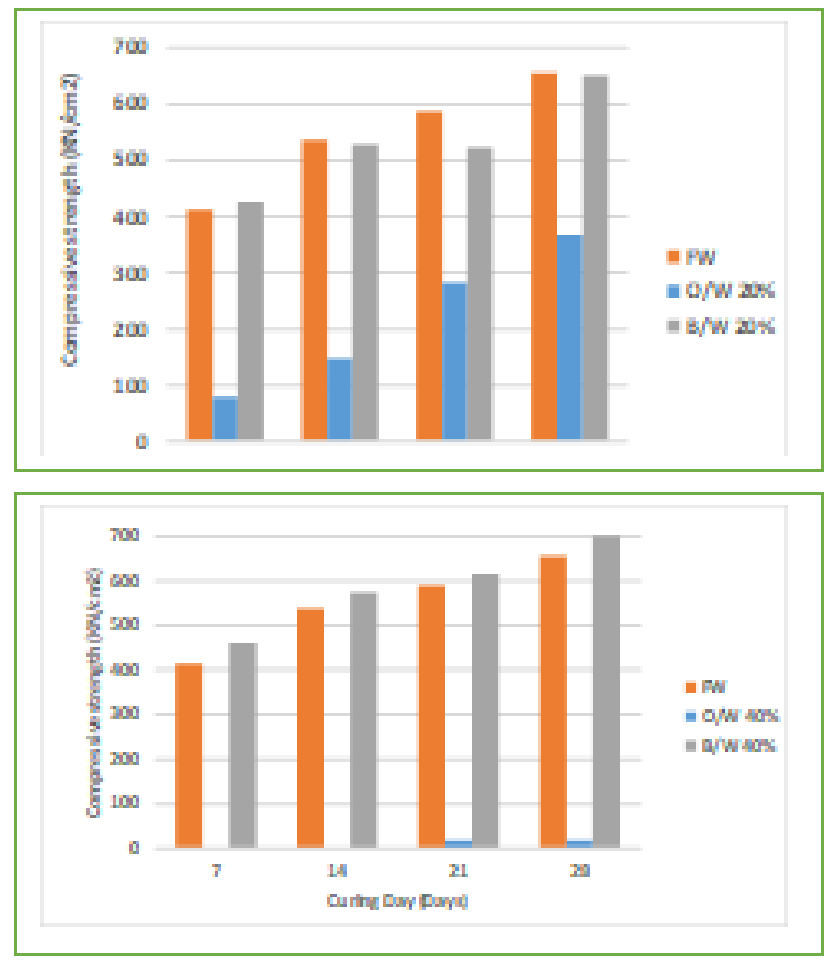

Figure 9: Compressive strength $\left(\mathrm{KN} / \mathrm{cm}^{2}\right)$ of mixes of different percentages (from 15 to 40 ) of olive oil mill wastewater to freshwater $\mathrm{O} / \mathrm{W}$ (blue bars) and brine water to freshwater B/W (grey bars).

\section{CONCLUSION}

We have investigated the effect of using brine water discharged from inland desalination plants and wastewater release from olive oil mill in concrete compressive strength. We have used different percentage of added brine and waste waters to freshwater volume in order to get insight into the detailed change in strength rate. We have noticed that adding olive oil mill wastewater increase concrete workability and changes surface color but will substantial weaken the strength at different percentages. In contrast, brine water have increased the strength rate for all samples in compared with freshwater mixes and surface color has been changed with faster dry rate. Many questions regarding to the $\mathrm{CO}_{2}$ emission rate after adding brine water and olive oil mill wastewater to concrete mixes, durability change, cost and possible local applications.

\section{ACKNOWLEDGMENT}

The author gratefully acknowledge the help of the staff at the structural engineering laboratory at Ajloun National University. This project is funded by Scientific Support Research Fund at Ajloun National University.

\section{REFERENCES}

[1] Neville, A.M. and Brooks, J.J., 1994. Concrete technology. England: Longman Scientific and Technical.

[2] Falah M. Wegian, 2010, Effect of seawater for mixing and curing on structural concrete, The IES Journal Part A Civil \& Structural Engineering 3(4):235-243.

[3] Akhtar Surahyo, 2019, concrete construction (Practical Problems and Solutions), ebook, Springer.

[4] Nabil Bouzoubaâ and M Lachemi, 2001, Selfcompacting concrete incorporating high volumes of class F fly ash: Preliminary results, Cement and Concrete Research 31(3):413-420.

[5] E.W. Gadzama*, O.J. Ekele, V.E. Anametemfiok and A.U. Abubakar, 2015, EFFECTS OF SUGAR FACTORY WASTEWATER AS MIXING WATER ON THE PROPERTIES OF NORMAL STRENGTH CONCRETE, International Journal of Science, Environment ISSN 2278-3687 (O) and Technology, Vol. 4, No 3, 2015, $813-825$.

[6] Mounir El Heloui, Rachida Mimouni, Fatima Hamadi, 2016, Impact of treated wastewater on groundwater quality in the region of Tiznit (Morocco), Journal of Water Reuse and Desalination (2016) 6 (3): 454-463.

[7] Haseeb Khan, Tabish Izhar, Neha Mumtaz, Abdul Ahad, 2015, Effect of Saline Water in Mixing and Curing on Strength of Concrete, IJSART - Volume 2 Issue 5.

[8] Asif Rashid Shaikh, V. M. Inamdar, 2016, Study of Utilization of Waste Water in Concrete, IOSR Journal of Mechanical and Civil Engineering, 2278-1684,p-ISSN: 2320-334X, Volume 13, Issue 4 Ver. II.

[9] Qingyong Guo, Lei Chen, Huijian Zhao, Jorge 
International Journal of Engineering Research and Technology. ISSN 0974-3154, Volume 13, Number 10 (2020), pp. 2831-2838

(C) International Research Publication House. https://dx.doi.org/10.37624/IJERT/13.10.2020.2831-2838

Admilson, Wensong Zhang, 2018, The Effect of Mixing and Curing Sea Water on Concrete Strength at Different Ages, MATEC Web of Conferences 142, 02004.

[10] Emre Sancak, 2015, Sodium Sulphate Effect on Cement Produced with Building Stone Waste, Jornal of Materials, Volume 2015 (12).

[11] Mukesh KumarI; Narendra Pratap SinghII; Sanjay Kumar SinghIII; Nakshatra Bahadur Singh, 2010, Combined effect of sodium sulphate and superplasticizer on the hydration of fly ash blended Portland $®$ cement, Material Research. 